\title{
Projecting the need for hip replacement over the next three decades: influence of changing demography and threshold for surgery
}

ARC Epidemiology

Unit, University of Manchester, M13 9PT

F Birrell

A Silman

\section{Department of}

Orthopaedics, UMAS

University of Lund,

Sweden

O Johnell

Correspondence to:

Professor A Silman.

Accepted for publication 20 April 1999

\begin{abstract}
Objectives-To estimate the requirement for total hip replacement in the United Kingdom over the next three decades Methods-Projection of age and sex specific hip replacements in the UK over 10 year intervals taking account of demographic change and the extrapolation of arthroplasty rates from Sweden; a country with recently introduced guidelines.

Results-Assuming no change in the age and sex specific arthroplasty rates, the estimated number of hip replacements will increase by $40 \%$ over the next 30 year period because of demographic change alone. The proportionate change will be substantially higher in men $(51 \%)$ than women $(33 \%)$, with a doubling of the number of male hip replacements in those aged over 85. Changes in the threshold for surgery may increase this further-up to double the current number.

Conclusion-A sharp rise in hip replacements will be needed to satisfy needs in the UK population over the next 30 years. (Ann Rheum Dis 1999;58:569-572)
\end{abstract}

Total hip arthroplasty (THR) is one of the most common operations electively performed on the National Health Service (NHS) and rheumatologists are frequently involved in the decision of whether to refer patients for arthro-

Table 1 Estimated UK age and sex specific arthroplasty rates for 1996

\begin{tabular}{lrrr}
\hline & $\begin{array}{l}\text { 1996 Population } \\
\text { of England } \\
\text { (1000s) }\end{array}$ & $\begin{array}{l}\text { Arthroplasties } \\
1995-6^{*}\end{array}$ & $\begin{array}{l}1996 \text { UK } \\
\text { THR Ratel } \\
100000\end{array}$ \\
\hline Men & & & \\
$0-54$ & 18588 & 1983 & 10.67 \\
$55-64$ & 2359 & 4164 & 176.52 \\
$65-74$ & 1926 & 5166 & 268.22 \\
$75-84$ & 1001 & 3708 & 370.43 \\
$85+$ & 235 & 560 & 238.30 \\
Total $>55$ & 5521 & 13598 & 246.30 \\
Total & 24109 & 15581 & 64.63 \\
Women & & & \\
$0-54$ & 17953 & 2272 & 12.66 \\
$55-64$ & 2418 & 4872 & 201.49 \\
$65-74$ & 2274 & 9626 & 423.31 \\
$75-84$ & 1626 & 8467 & 520.73 \\
$85+$ & 679 & 1881 & 277.03 \\
Total $>55$ & 6997 & 24846 & 355.10 \\
Total & 24950 & 27118 & 108.69 \\
Total & & & \\
$0-54$ & 36541 & 4255 & 11.64 \\
$55-64$ & 4777 & 9036 & 189.16 \\
$65-74$ & 4200 & 14792 & 352.19 \\
$75-84$ & 2627 & 12175 & 463.46 \\
$85+$ & 914 & 2441 & 267.07 \\
Total $>55$ & 12518 & 38444 & 307.11 \\
Total & 49059 & 42699 & 87.04 \\
\hline Data & & & \\
\hline
\end{tabular}

^Data grossed.
Table 2 Projected total hip arthroplasties in UK, based on projected population changes alone

\begin{tabular}{lrrrr}
\hline Age group & $\begin{array}{l}\text { Estimated } \\
1996\end{array}$ & $\begin{array}{l}\text { Projected } \\
2006\end{array}$ & $\begin{array}{l}\text { Projected } \\
2016\end{array}$ & $\begin{array}{l}\text { Projected } \\
2026\end{array}$ \\
\hline Men & & & & \\
55-64 & 5006 & 6220 & 6402 & 7431 \\
$65-74$ & 6201 & 6293 & 8020 & 8261 \\
$75-84$ & 4397 & 5001 & 5612 & 7442 \\
$85+$ & 670 & 860 & 1115 & 1513 \\
Total $>55$ & 16274 & 18374 & 21149 & 24648 \\
Women & & & & \\
$55-64$ & 5894 & 7332 & 7614 & 8676 \\
$65-74$ & 11616 & 10942 & 13868 & 14422 \\
$75-84$ & 10128 & 10258 & 10154 & 13310 \\
$85+$ & 2175 & 2621 & 2942 & 3266 \\
Total $>55$ & 29812 & 31154 & 34578 & 39674 \\
Total & & & & \\
55-64 & 10897 & 13549 & 14009 & 16109 \\
$65-74$ & 17807 & 17367 & 22068 & 22847 \\
$75-84$ & 14515 & 15387 & 16059 & 21157 \\
$85+$ & 2847 & 3491 & 4086 & 4845 \\
Total >55 & 46066 & 49793 & 56222 & 64957 \\
\hline
\end{tabular}

plasty. The operation is effective, with measurable improvements in function and pain relief. The cost is high, however. In 1995/6 over 38000 primary THRs were performed in NHS hospitals in England, with a further 4000 revision procedures. ${ }^{2}$ Thus, this procedure constitutes two thirds of the total cost of hospital treatment of osteoarthritis in the UKestimated in 1992 at a total of $£ 231.3$ million. ${ }^{3}$ Health economic analysis suggests though it is cost effective. The cost-utility analyses performed estimate that the cost per quality adjusted life year (QALY) for THR to be around $£ 700$, compared with $£ 1000-12000$ for coronary artery bypass grafting and $£ 3000$ for a kidney transplant. ${ }^{45}$ To plan for the future provision of hip arthroplasty, it is, however necessary to consider the trends in the three key variables concerned; these are: (a) projected changes in the occurrence of severe hip morbidity, (b) demographic change affecting the denominator population and (c) changing threshold of the indication for surgery.

Moderate to severe osteoarthritis is the commonest indication for arthroplasty, accounting, for example, for over three quarters of operations in Sweden. ${ }^{6}$ Despite this, there are very few data on trends in the incidence of clinically significant osteoarthritis in Europe. Trends in the occurrence of radiographic hip osteoarthritis can be crudely estimated from a comparison of prevalence surveys; and such data are available for those older than 40 in Malmö over the past 30 years..$^{7-9}$ In these studies, the prevalence was constant over this period at $1.9-2.3 \%$, with little difference between the sexes. Surveys performed in the 


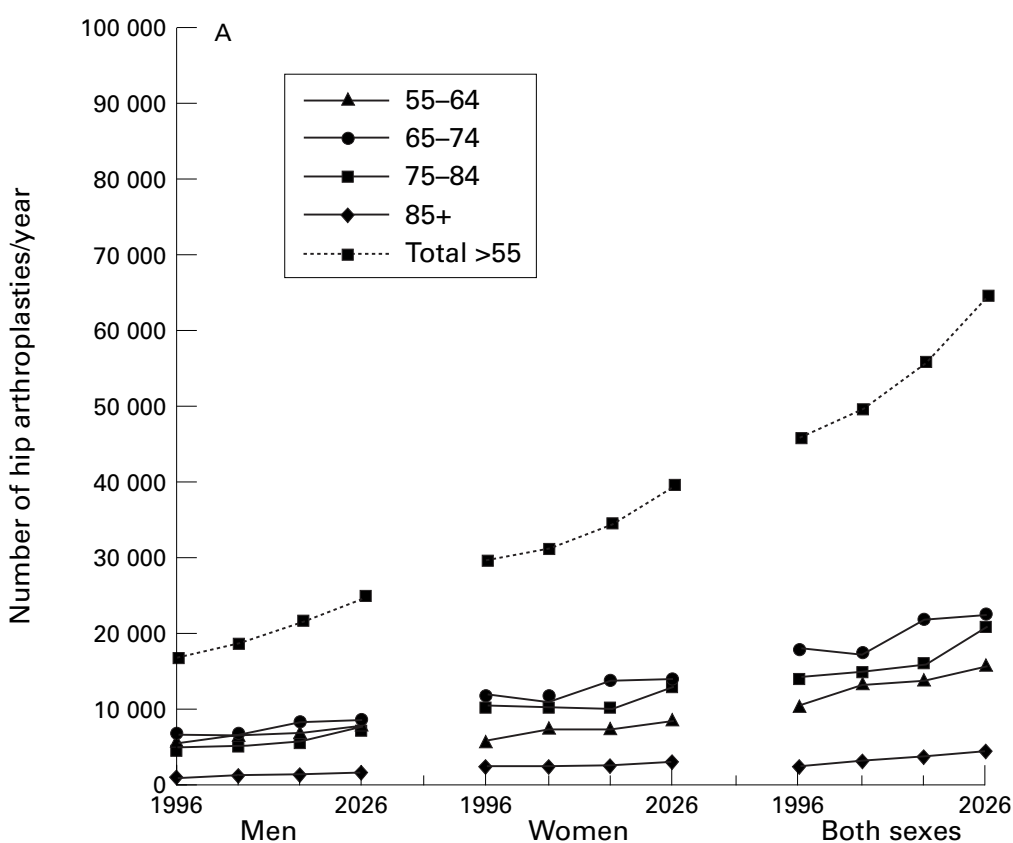

Sex and year of projection

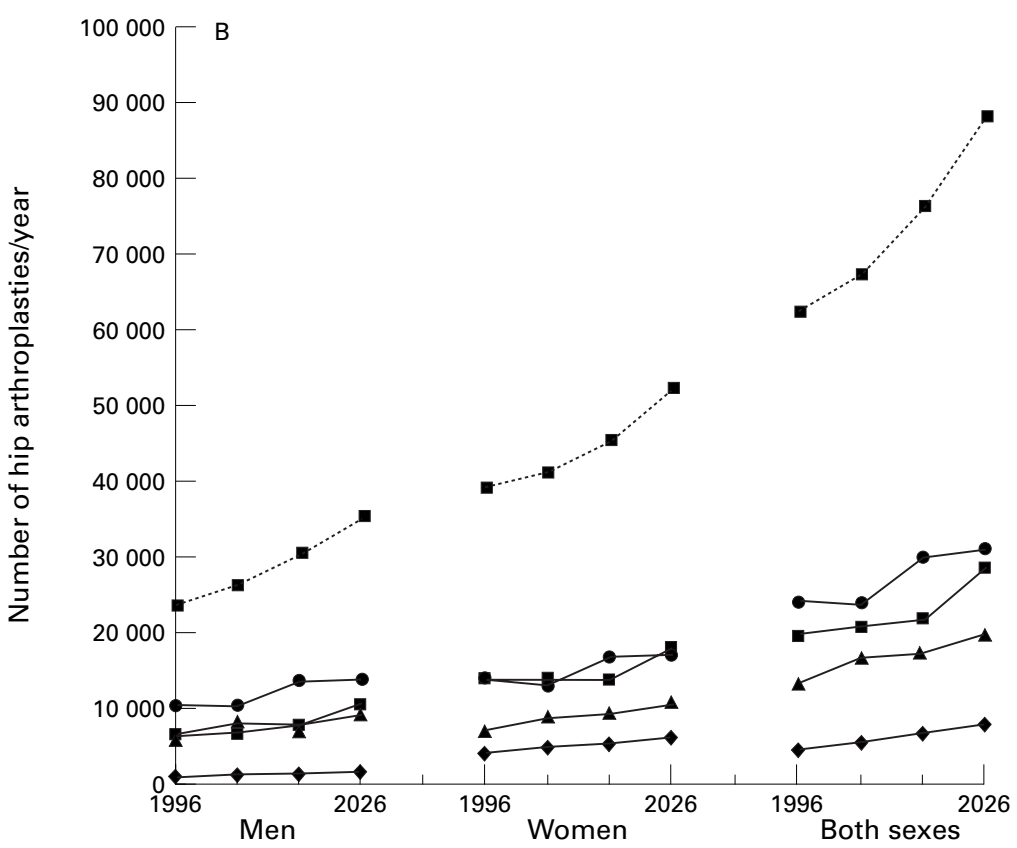

Sex and year of projection

Figure 1 (A) Projected total hip arthroplasties in UK, based on projected population changes and constant arthroplasty rates. (B) Projected total hip arthroplasties in UK, based on projected population changes and Swedish arthroplasty rates.

UK have used differing criteria and geographical locations, but no consistent trend of changing prevalence of osteoarthritis was found..$^{10-12}$ We have therefore assumed that there will be no important change in the underlying incidence or natural history of hip osteoarthritis over the period considered. Thus, the influence of changing demography and threshold for surgery form the basis for this report.

As a consequence of the increasing survival in the elderly, the absolute numbers in the population at risk for disorders with a predilection for the elderly, such as hip osteoarthritis, will increase. The threshold for surgery may also change. Several factors influence this threshold, including referral from primary
Table 3 Projected total hip arthroplasties in UK, based on projected population changes, plus Swedish arthroplasty rates

\begin{tabular}{lrrrr}
\hline Age group & $\begin{array}{l}\text { Estimated } \\
1996\end{array}$ & $\begin{array}{l}\text { Projected } \\
2006\end{array}$ & $\begin{array}{l}\text { Projected } \\
2016\end{array}$ & \multicolumn{1}{c}{$\begin{array}{l}\text { Projected } \\
2026\end{array}$} \\
\hline Men & & & & \\
$55-64$ & 6321 & 7854 & 8084 & 9383 \\
$65-74$ & 10338 & 10490 & 13369 & 13772 \\
$75-84$ & 6128 & 6969 & 7821 & 10371 \\
$85+$ & 804 & 1032 & 1339 & 1816 \\
Total $>55$ & 23590 & 26345 & 30612 & 35342 \\
Women & & & & \\
55-64 & 7178 & 8930 & 9274 & 10567 \\
$65-74$ & 13980 & 13170 & 16691 & 17358 \\
$75-84$ & 13756 & 13933 & 13792 & 18078 \\
$85+$ & 4173 & 5029 & 5646 & 6268 \\
Total $>55$ & 39088 & 41063 & 45402 & 52271 \\
Total & & & & \\
$55-64$ & 13505 & 16791 & 17361 & 19963 \\
$65-74$ & 24304 & 23703 & 30120 & 31183 \\
$75-84$ & 19740 & 20925 & 21839 & 28772 \\
$85+$ & 4869 & 5970 & 6988 & 8286 \\
Total $>55$ & 62418 & 67389 & 76308 & 88203 \\
\hline
\end{tabular}

care, number of trained orthopaedic surgeons performing arthroplasties, bed and theatre space for elective operations and the existence and application of criteria for surgery. Elucidating the contribution of these factors is difficult, but we have chosen to examine the effect of varying threshold using a further model. Age and sex specific arthroplasty data are available from Sweden - a country where the occurrence of hip disease is likely to be similar to the UK. These data can be applied to population projections to model the effect of a different threshold. We have therefore considered individually, and in combination, the influence of demographic change and alteration of arthroplasty rates to the total numbers of THR required in the UK over the next 30 years.

\section{Methods}

The Office of Population Censuses and Surveys (OPCS, now the Office of National Statistics) 1994 based population projection was used, as the most recent accurate base denominator. ${ }^{13}$ The current number of THRs was identified from the Hospital Episode System (HES) in England data from $1995 / 6^{2}$ and the age specific THR rates for the UK calculated. Data are derived from the census to estimate the age and sex specific population structure over the next 30 years assuming constant birth, death and migration rates. ${ }^{13}$ The THR rate was then applied to those projections, to estimate the number of procedures necessary for the years 2006, 2016 and 2026. We only analysed data in those 55 years of age or older as the incidence of hip osteoarthritis below this age is low and primary osteoarthritis is not the most common indication in this age group. Indeed, less than $10 \%$ of THRs are performed before the age of $55 .^{2}$

We then modelled the effect of Swedish arthroplasty rates on the number of THRs. Hip arthroplasty and population data for Sweden were supplied by the Swedish central registryEpidemiologiskt Centrum, Socialstryrelsen (personal communication). Data are collected in Sweden on all operations and inpatient episodes. The data presented are a summary of all unique patient identifiers located by either 
method. This approach minimises underestimation of THRs because of missed or miscodes.

\section{Results}

The total population of the UK was nearly 59 million in 1996, of whom 50 million resided in England. The age and sex specific frequencies of hip arthroplasty are shown in table 1 with the base population figures and number of arthroplasties in England used to estimate them. Table 2 shows the projected number based on applying these age specific rates applied to the projected UK population. Thus assuming no change in the age and sex specific arthroplasty rates, the estimated THRs would increase by $40 \%$ over the 30 year period because of demographic change. While both sexes contribute in absolute terms almost equal numbers to the increase, the proportionate change will be substantially higher in men $(51 \%)$ than women $(33 \%)$. The proportionate change would be higher in middle aged and very elderly with a doubling of the number of hip replacements in those men aged over 85 (see fig 1A). Applying current Swedish THR rates to projected demographic changes gives a further set of predictions (table 3 and fig 1B). Given that current Swedish THR rates are almost double those of the UK for the first three age bands studied and $50 \%$ higher overall, this model predicts a large increase-by 2026 the predicted total number of THRs is almost double the 1996 total based on UK rates. Under the combination of assumptions the number of THRs in UK in those over 75 will increase by $42 \%$ by 2006 , $55 \%$ by 2016 and $113 \%$ by 2026 .

\section{Discussion}

We have used existing data on the THR activity in England and Sweden, with current demographic projections to estimate the numbers of THRs that were/will be carried out in the UK in 1996, 2006, 2016 and 2026. Consideration of the demographic changes alone suggests that the requirement for THR will have increased by $40 \%$ by 2021 , with the greater proportionate increase across the middle aged and very elderly. However, if arthroplasty rates approached those observed in Sweden-which might arise if UK surgeons applied the Swedish guidelines for THRthere may be a doubling of existing demand over the same time scale.

We opted to use the data from Sweden to represent the situation in a country with a similar universal health care system and background occurrence of disease, though where an attempt has been made to prioritise demand. The Swedish guidelines use agreed criteria, which in theory should be applicable elsewhere. The Swedish model predicts a large increase in arthroplasties. As this is not explained by a large difference in osteoarthritis prevalence $^{7-10}$ and the Swedish criteria show comparable indications, there is no a priori reason why age specific arthroplasty rates should be lower in England. Therefore, other factors influencing this threshold for surgery are implicated. These include referral from primary care, number of trained orthopaedic surgeons performing arthroplasties, bed and theatre space for elective operations and the existence and application of criteria for surgery. As the NHS moves towards a consultant delivered service, these factors are likely to change in the direction of favouring more THRs.

In Sweden, the aim of guideline introduction was to reduce waiting lists and target intervention at those with the greatest need, rather than provide objective criteria. ${ }^{14}$ Patients are prioritised into one of three groups based on pain or serious functional impairment, plus the additional requirement of radiographic changes, with at least $50 \%$ reduction of joint space. Guidelines do exist for total hip replacement in some other countries, including the $\mathrm{US}^{15}$ and New Zealand. ${ }^{16}$ The NIH consensus conference criteria lack objective standard indications, however, relying on "radiographic ...joint damage and moderate-to-severe persistent pain or disability ...not substantially relieved by ...extended non-surgical management". ${ }^{15}$ The New Zealand priority criteria provide a more structured approach, scoring pain $(40 \%)$, function $(20 \%)$, movement/deformity $(20 \%)$ and other factors $(20 \%)$ to give an overall score out of $100 .{ }^{16}$ These have advantages in ensuring equitable delivery of health care and therefore resource allocation, but as these detailed data are not available on hip replacement patients in England, direct comparison with New Zealand cannot be made. If guidelines were introduced in the UK, this could allow us to examine whether the known variation in orthopaedic provision around the country ${ }^{17}$ is responsible for the lower replacement rates we have demonstrated. An international consensus would be even more useful - possibly based on the New Zealand criteria.

There are several limitations to these estimates, which relate to both the arthroplasty data and the population projections. Firstly, it has been assumed that there will be no underlying change in the age specific incidence rate of hip osteoarthritis. This was based on data from serial radiographic surveys, ${ }^{7-9}$ which may not reflect changes in the natural history of the disorder. Data from the Mayo clinic showed increased uptake of hip arthroplasty over two decades from $1969-90,{ }^{18}$ but the changes observed are subject to many influences, particularly in the availability or demand for surgery. Change in the incidence or severity of osteoarthritis cannot be inferred by this type of study.

Secondly, the demographic projections themselves may be inaccurate, as they assume that rates of mortality, fertility and migration will stay constant over 30 years. Such assumptions are a necessary part of any projection to assist long term planning, but there is good reason to expect projection to 2026 at least to be accurate with regard to arthroplasty. As the cohort entering the higher risk age bands has already been born, only changes in migration and mortality rate apply and the projections are likely to be quite accurate. We have made the assumption that the underlying health of the elderly, specifically the risks and benefits of hip 
surgery, will remain unaltered despite the increasing absolute numbers.

Thirdy, no allowance has been made for private operations - this model is best interpreted as a total needs estimate, including both NHS and private operations. The optimal way of meeting this requirement is beyond the remit of this paper.

The proportion of THRs done for osteoarthritis may differ between the two countries. UK age specific data are not available, but grouping all THRs in England for 1989, only $49 \%$ were coded with a principal diagnosis of primary osteoarthritis. ${ }^{17}$ This would suggest that the arthroplasty rate for osteoarthritis in the UK is even lower than Sweden. This will lead to underestimation of THR in all of the projections.

Finally, revision operations have not been analysed separately, given the uncertainties in estimating revision rate occurring in an estimated primary arthroplasty population. Revision arthroplasty is increasing in the UK, accounting for $4.1 \%$ of THR workload in 1980 and $12.1 \%$ in $1989 / 90 .{ }^{17}$ This will also lead to underestimation of THR in all of the projections, which must therefore be considered conservative.

In conclusion, a sharp rise in hip replacements will be needed to satisfy needs in the UK population over the next 30 years.

We thank Kurt-Lennart Spetz and Andres Leimanis from the Epidemiogiskt Centrum, Socialstyrelsen, for providing data on hip replacements in Sweden and Anna Kvalvik for translating the Swedish hip replacement guidelines. Also, thanks to Cathy Bryan for final setting of the figure.

FNB is an ARC Clinical Epidemiology Training Fellow.
1 Bellamy N, Buchanan WW, Goldsmith $\mathrm{CH}$, Campbell J, Stitt L. Validation study of WOMAC B a health-status instrument for measuring clinically-important patientrelevant outcomes following total hip or knee arthroplasty in osteoarthritis. J Orthop Rheumatol 1988;1:95-108.

2 Hospital Episode System (HES) Data. London: Department of Health, 1996.

3 Office of Health Economics. Arthritis. London: OHE, 1992.

4 Williams A. Economics of coronary artery bypass grafting. BMJ 1985;291:326-9.

5 May PC. Costs per case or costs per Quality-AdjustedLife-Year? How do we assess value for money. In: Wallace WA, eds. Foint replacement in the 1990s. Clinical studies, financial implications and marketing approaches. Bury St Edmonds: Mechanical Engineering Publications Ltd,

6 Socialstyrelsen: Uppföljning och utvärdering av 1992 års nationella vårdgaranti. Stockholm: Socialstyrelsen, 1993 11.

7 Danielsson LG. Incidence and prognosis of coxarthrosis. ACTA Orthop Scand 1964;S66:1-114.

8 Danielsson LG, Lindberg HL, Nilsson B. Prevalence of coxarthrosis. Clin Orthop 1984;191:110-15

9 Danielsson LG, Lindberg HL. Prevalence of coxarthrosis in an urban population during four decades. Clin Orthop 1997;342:106-10.

10 Kellgren JH, Lawrence JS. Osteoarthrosis and disk degeneration in an urban population. Ann Rheum Dis 1958; 17:388-97.

11 Wilcock GK. The prevalence of osteoarthrosis of the hip requiring total hip replacement in the elderly. Int J Epidemiol 1979;8:247-50.

12 Arden NK, Griffiths GO, Hart DJ, Dotle DV, Spector TD The association between osteoarthritis and osteoporotic fracture: the Chingford study. Br J Rheumatol 1996;35: 1299-304.

13 Office of Populations, Censuses and Surveys (OPCS) 1994-based National population projections. Series PP2, no.20. London: HMSO, 1996.

14 Vårdgarantin: Patienterna delas in i tre prioriteringsgrupper. Stockholm: Socialstyrelsen, 1991: 11.

15 Total hip replacement-NIH consensus development panel on total hip replacement. JAMA 1995;273:1950-6.

16 The New Zealand priority criteria project. Part 1: overview. Hadorn DC, Holmes AC. BMJ 1997;314:131-4.

17 Hospital Episode System (HES) Data. London: Department of Health, 1990

18 Madhok R, Lewallen DG, Kurland RL, Melton LJ III Trends in the utilization of primary total hip arthroplasty, 1969 through 1990: a population-based study in Olmsted county, Minnesota. Mayo Clin Proc 1993;68:11-18. 